\title{
Estimation of depth and charge weight for a shallow underwater explosion using cut off frequencies and ray-trace modeling
}

\author{
So Gu Kim ${ }^{1}$, , Yefim Gitterman², Orlando Camargo Rodriguez ${ }^{3}$ \\ ${ }^{1}$ Korea Seismological Institute, Goyang, 410-734, Republic of Korea \\ ${ }^{2}$ Geophysical Institute of Israel, P.O. BOX, 182, Lod, 71100, Israel \\ ${ }^{3}$ University of Algarve, LARSyS, Campus de Gambelas, Faro, 8005-139, Portugal
}

\section{Email address:}

sogukim@hanmail.net (So Gu Kim)

To cite this article:

So Gu Kim, Yefim Gitterman, Orlando Camargo Rodriguez. Estimation of Depth and Charge Weight for a Shallow Underwater Explosion Using cut off Frequencies and Ray-Trace Modeling. Science Research. Vol. 1, No. 6, 2013, pp. 75-78.

doi: $10.11648 /$ j.sr.20130106.11

\begin{abstract}
In this paper we utilized an additional forward model to estimate the detonation depth using normal modes (cutoff frequencies) to estimate the detonation depth and net explosive weight. With detonation depth the net explosive weight for a shallow underwater explosion could also be determined. The hydroacoustic wave propagation in shallow channel was confirmed via ray-tracing method. We found cutoff frequencies of the reflection off the ocean bottom to be 8.5 $\mathrm{Hz}, 25 \mathrm{~Hz}$, and $43 \mathrm{~Hz}$ while the cutoff frequency of the reflection off the free surface to be $45 \mathrm{~Hz}$ including $1.01 \mathrm{~Hz}$ for the bubble pulse, and also found the cutoff frequency of surface reflection to well fit the ray-trace modeling. Our findings led us to the net explosive weight of the ROKS Cheonan to be approximately $136 \mathrm{~kg}$ TNT at a depth of about $8 \mathrm{~m}$ within an ocean depth of around $44 \mathrm{~m}$.
\end{abstract}

Keywords: Cutoff Frequency, Total Reflection, Ray-Trace Modeling, Cycle Distance, Bubble Pulse,

Net Explosive Weight

\section{Introduction}

The underwater explosion (UWE) vis-à-vis the ROKS Cheonan took place off the coast of Baengnyeong Island in the Yellow Sea of the Korean peninsula on March 26, 2010 (see Figure 1). Considerable efforts have been devoted to estimate the net explosive weight of this UWE using spectral analysis and analytical approach including simulation of boundary element method [1-2]. These attempts have typically used ad hoc models of the relationship between bubble pulse period and net explosive weight or have been based on 3D shape simulation by BEM [1-2]. This paper presents the relationship between the cutoff frequencies and the detonation depth resulting in obtaining the net explosive weight, including application of ray-trace modeling for confirmation of estimation. We utilized cutoff frequencies to estimate the detonation and ocean depths including the bubble pulse period for the extrapolated net explosive weight. We also verified whether our estimated source depth fitted the observed one

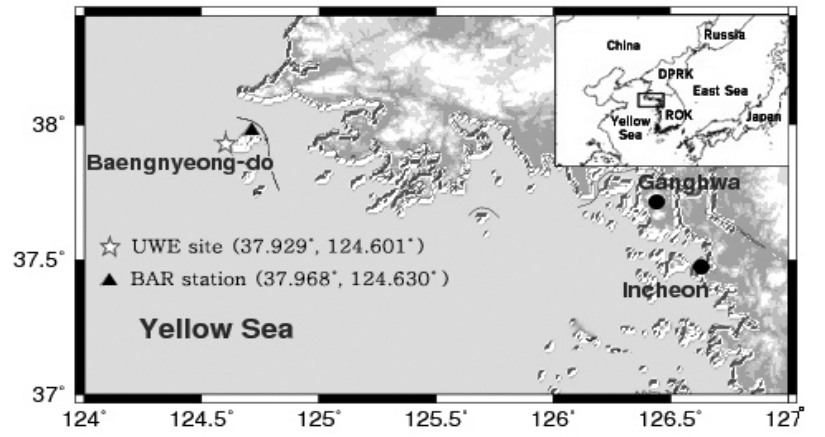

Figure 1. Map of the UWE site. The star, triangle and circles indicate the UWE site, seismic station and ports, respectively.

using ray-trace modeling in the shallow channel. The compelling reason of this study is to estimate the net explosive weight (NEW) for a very shallow underwater explosion $(<50 \mathrm{~m})$ using only cutoff frequencies and Rayleigh-Willis equation [1-2]. The NEW estimation is possible using a cutoff frequency and the bubble pulse period from spectral analysis relating to the Rayleigh- 
Willis equation since it is a function of detonation depth and NEW.

\section{Cutoff Frequencies and Normal Modes}

Shallow water $(<200 \mathrm{~m})$ sound fields are defined in terms of normal mode propagation. The normal mode propagation without attenuation are those for which water depth is greater than one-quarter wavelength $(H>\lambda / 4$, $\mathrm{H}=$ water depth, $\lambda$ =wavelength). The frequency corresponding to $\mathrm{H}=\lambda / 4$ is termed the cutoff frequency of the waveguide. Waves with frequencies lower than the cutoff frequency are propagated in the channel only with attenuation and are not effectively trapped in the duct of the layer. There is no mode propagation below the cutoff frequency.

Note Snell's law: $C_{2} \sin \theta_{1}=C_{1} \sin \theta_{2}\left(C_{1}\right.$ and $C_{2}$ are velocity of upper layer and lower layer respectively and $\theta_{1}$ and $\theta_{2}$ are angles of incidence and transmission respectively). Taking one particular incident angle $\theta_{\mathrm{C}}$ called a critical angle which is the transmission limit angle $\left(90^{\circ}\right)$, when the incident angle is greater than $\theta_{\mathrm{C}}$, all the incident waves are reflected in the water layer and no energy is transmitted in the sediment layer [3]. The velocity with which the wave front progresses is dependent on the incident angle $\theta_{1}$ and will always be greater than the medium velocity $\mathrm{C}_{1}$ of each downward or upward ray. To focus on the critical angle $\theta_{C}=\theta_{1}$, the cutoff frequency for each mode is simplified. If the incident angle is greater than the critical angle, the normal mode propagation starts in a waveguide. The wave propagates by multiple reflections at an incident angle between the grazing angle and critical angle for total reflection under the condition of constructive interference in the reflection off the ocean bottom [3] in case of $\mathrm{C}_{1}<\mathrm{C}_{2}$.

According to Urick [4], the cutoff frequency is presented for the first mode as follows:

$$
\mathrm{f}_{\mathrm{H}}=\mathrm{C}_{1}(2 \mathrm{n}-1) / 4 \mathrm{H}\left[1-\left(\mathrm{C}_{1} / \mathrm{C}_{2}\right)^{2}\right]^{-1 / 2} \mathrm{n}=1,2 \ldots \ldots
$$

where $C_{1}$ is the downward velocity of the water layer of thickness $\mathrm{H}$ with mode number $\mathrm{n}$ and $\mathrm{C}_{2}$ is the velocity at the rigid bottom (sediment or basement). This equation is reduced to $\mathrm{f}_{\mathrm{H}}=\mathrm{C}_{1} / 4 \mathrm{H}$ when $\mathrm{C}_{1}<<\mathrm{C}_{2}$ which is the cutoff frequency of the first mode for the water column reverberation. i.e. the ocean depth for the cutoff frequency $\mathrm{H}=\mathrm{C}_{1} / 4 \mathrm{f}_{\mathrm{H}}$.

For the upward velocity $\left(\mathrm{C}_{1}\right)$ with a water layer of thickness $d$ and $C_{0}$ the acoustic velocity in the atmosphere, in the case of incident waves in water reflecting off an airwater interface, $\mathrm{C}_{1}>\mathrm{C}_{0}$ yields $\theta_{\mathrm{t}}<\theta_{\mathrm{i}}$ where $\theta_{\mathrm{t}}$ is a maximum transmitted angle and the transmitted wave is refracted closer to the normal $\left(13.1^{\circ}\right)$ in case of grazing incidence angle of $90^{\circ}$. According to Snell's law, i. e. sin $\theta_{\mathrm{i}} / \sin \theta_{\mathrm{t}}=\mathrm{C}_{1} / \mathrm{C}_{0}$ and the grazing incidence $\left(\theta_{\mathrm{i}}=90^{\circ}\right)$ and there are small transmitted waves with $\theta_{\operatorname{tmax}}=\arcsin \left(\mathrm{C}_{0} / \mathrm{C}_{1}\right)$, resulting in shock waves as well as acoustic waves. Therefore we take into account the cutoff frequency of the surface reflection at the boundary without transmission, especially as sound velocity increases with depth in the case of isothermal velocity profile during the cold season [5].

$$
\mathrm{fd}=\mathrm{C}_{1}(2 \mathrm{n}-1) / 4 \mathrm{~d}\left[1-\left(\mathrm{C}_{0} / \mathrm{C}_{1}\right)^{2}\right]^{-1 / 2} \mathrm{n}=1,2, \ldots
$$

The equation is also reduced to $\mathrm{fd}=\mathrm{C}_{1} / 4 \mathrm{~d}$ for the first mode when $\mathrm{C}_{0}<<\mathrm{C}_{1}$. In case of a reflection coefficient $=-$ 1 , there is a total reflection. The transmission is negligible and the incident waves are always reflected at the free surface and become channel waves neglecting evanescent modes. Therefore, the detonation depth for the first mode $\mathrm{d}=\mathrm{C}_{1} / 4 \mathrm{fd}$.

\section{Ray-trace Modeling for Hydroacoustic Waves}

When temperature does not vary with depth (isothermal profile), the sound velocity linearly increases with depth due to the hydrostatic pressure. This special case is going to be applied to the ray-trace modeling and this underwater explosion. All the ray paths are therefore refracted upward and propagate by successive bounces off the surface (see Figures 2 and 3). This configuration is called a surface channel [5]. Such phenomena are often found in the polar sea or enclosed seas during the cold season like the situation in this study. Ray-trace modeling (in the context of underwater acoustics) is a computational technique based on the calculation of propagating rays which correspond to the normal direction to the wavefront [6]. The calculation of the rays can be used to estimate the acoustic pressure induced in the underwater waveguide by the pressure of an acoustic source [7]. We can observe the predominant propagation of sound waves at around $8 \mathrm{~m}$ in the shallow channel by ray-tracing but we can also observe small peaks at around $45 \mathrm{~Hz}$ via spectral analysis since nondispersive hydroacoustic waves are converted into seismic waves with high attenuation. The amplitudes steeply decay passing through the FIR filtration near Nyquist frequency $(50 \mathrm{~Hz})$ during the formation of seismic waveform data (see Figures 4 and 5). The use of seismic data with high sampling rate (e.g. $200 \mathrm{~Hz}$ ) or the hydrophone data with high frequency signals would produce larger amplitude of spectral anomalies at $45 \mathrm{~Hz}$ in this case. Shapira [8] found the quality factor, Q of the sea water is found to be more than 10 times higher than that of the land from underwater explosions off the coast of Israel. These results can also be explained by the fact that the island formation of a low-quality factor $\mathrm{Q}$ contributed to small amplitudes of the spectra of this UWE.

For the isothermal configuration with the linear law $\mathrm{C}(\mathrm{z})$ $=1458.53+0.9425 \mathrm{z}$ as a function of depth $\mathrm{z}$ in this study, the rays of hydroacoustic waves would be arcs of circles reflected on the surface showing a periodic structure with a 
horizontal cycle distance $\mathrm{D}_{\mathrm{C}}$ [5] for a ray bouncing off the surface with a grazing angle $\mathrm{u}$ (Figure 2). We can derive a horizontal cycle distance $\left(\mathrm{D}_{\mathrm{C}}\right)$, propagation time over one cycle $\left(\mathrm{T}_{\mathrm{C}}\right)$, and bottoming depth $\left(\mathrm{Z}_{\mathrm{C}}\right)$ using Snell's law in differential form and a radius of curvature to model the ray path contingent on the isothermal configuration of the cold sea pertinent to this study.

$$
\begin{gathered}
\mathrm{D}_{\mathrm{C}}=2 \int_{a}^{b} R(u) \cos u d u \\
\mathrm{Z}_{\mathrm{C}}=\int_{a}^{b} R(u) \sin u d u \\
\mathrm{~T}_{\mathrm{C}}=2 \int_{a}^{b} R(u) \sec u d u
\end{gathered}
$$

where $\mathrm{R}(\mathrm{u})=$ curvature of radius and $\mathrm{R}(\mathrm{u})=-\mathrm{Cv} / \mathrm{g}$ when $\mathrm{Cv}$ is a vertex sound velocity at a grazing angle $u=0$ in this case, $\mathrm{g}=$ velocity gradient, and $\mathrm{a}$ and $\mathrm{b}$ are grazing angles at depth $\mathrm{Z}=0$ and $\mathrm{Z}=$ vertex.

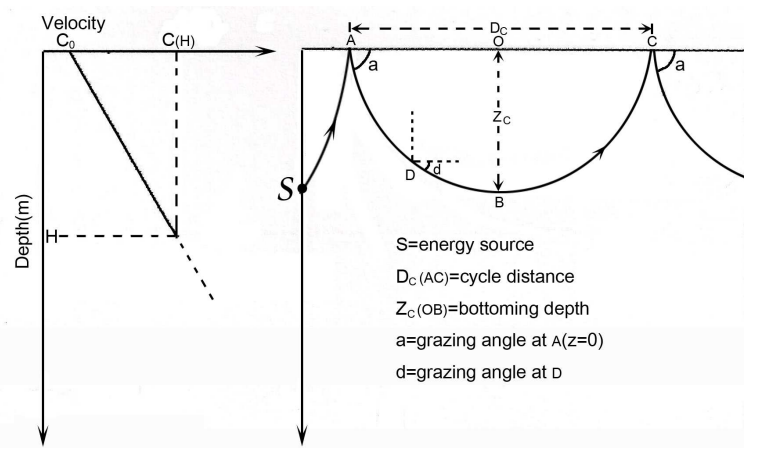

Figure 2. Ray geometry for an isothermal sound velocity profile that increases with depth due to the hydrostatic pressure.

Provided the attenuation is not too large and dispersion is little, we estimated a horizontal cycle distance $\left(\mathrm{D}_{\mathrm{C}}\right)$ at about $325 \mathrm{~m}$ with group velocity of $1460 \mathrm{~m} / \mathrm{s}$ at a bottoming depth $\left(\mathrm{Z}_{\mathrm{C}}\right)$ of about $8 \mathrm{~m}$ [1-2]. The horizontal cycle distance is clearly visible (Figure 3 ) and is strongly associated with the group velocity carrying energy along a ray or beam shift [9-10]. There are about 10 wavelengths in each horizontal cycle distance implying that there must be the total reflection (reflection coefficient of -1 ) on the surface [4]. We can estimate the cutoff frequency of this hydroacoustic wave propagation at around $45 \mathrm{~Hz}$ taking into account about $33 \mathrm{~m}$ wavelength in this ray-tracing modeling. It is notable that surface reflected arrivals usually suffer very little loss in the horizontal cycle distance with group velocity. As a result, we could prove that the source (detonation) depth at $8 \mathrm{~m}$ which was $2.5 \mathrm{~km}$ away from the coast contributed to the shallow reflection from the free surface using ray-trace modeling.

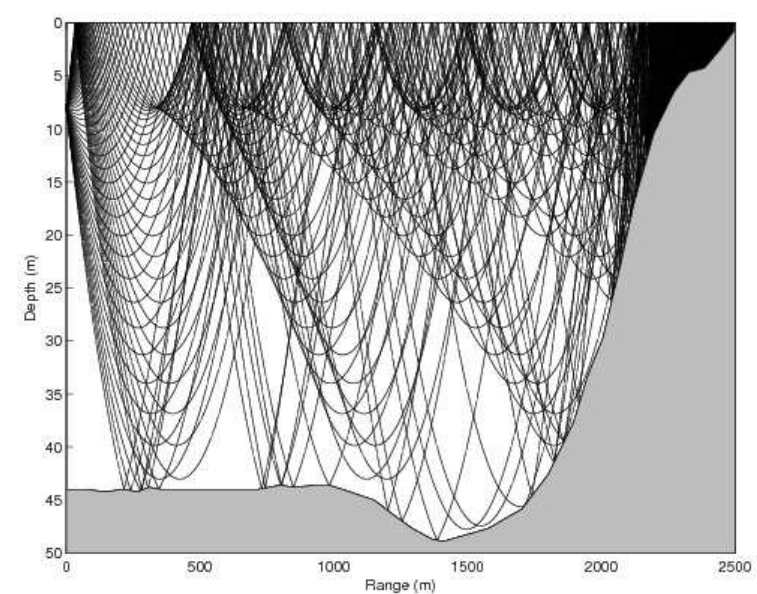

Figure 3. Ray-tracing based on hydroacoustic wave speed in the early spring season with a UWE source detonated at a depth of $8 \mathrm{~m}$ near the Baengnyeong-do in the Yellow Sea. Rays in a surface channel refract away from the sea surface and are going up to the surface due to the increase of sound velocity with depth in the maritime environment of the cold season.

\section{Results of Spectral Analysis and Discussion}

The previous study [1-2] determined bubble and reverberation effects of hydroacoustic waves as well as the seismic yield through seismic and acoustic waves, including the bubble pulse period of $0.990 \mathrm{~s}(1.01 \mathrm{~Hz})$ which was essential to estimate a net explosive weight using Rayleigh-Willis equation without information of a source depth. Here we estimate the source depth first and then we simply determine a NEW with known bubble pulse period and the detonation depth. Spectral analysis was applied for $\mathrm{P}$-wave and the summation of $\mathrm{P}$-wave and surface wave trains. We estimated the cutoff frequencies for the reflection off the ocean bottom and surface as well as the bubble pulse period. Cutoff frequencies from the ocean bottom and surface as well as the bubble pulse frequency are observed both on the P-wave spectra (in Figure 4) and the summation of $\mathrm{P}$ and Rayleigh wave spectra (in Figure 5). Cutoff frequencies are $8.5,25,43 \mathrm{~Hz}$ from the bottom reflection and $45 \mathrm{~Hz}$ from the surface reflection. The bubble pulse $(1.01 \mathrm{~Hz})$ which was determined from the previous study [1] is not displayed on the left figure in Figure 4 but it appears on the right figure in Figure 4 because the bubble pulse period is $0.990 \mathrm{~s}$ after $\mathrm{P}$-wave arrival at 12:21:59.24. On the other hand in Figure 5, we can observe all spectral anomalies at $17.5 \mathrm{~Hz}$ and $35 \mathrm{~Hz}$ as well as $8.5 \mathrm{~Hz}, 25 \mathrm{~Hz}$, and $43 \mathrm{~Hz}$ (cutoff frequencies of reflection off the bottom) and $45 \mathrm{~Hz}$ (cutoff frequency of reflection off the free surface) as well as $1.01 \mathrm{~Hz}$ (bubble pulse). There are more salient spectral peaks in Figure 5 due to amalgamation of $\mathrm{P}$ and surface waves (Rayleigh waves). 


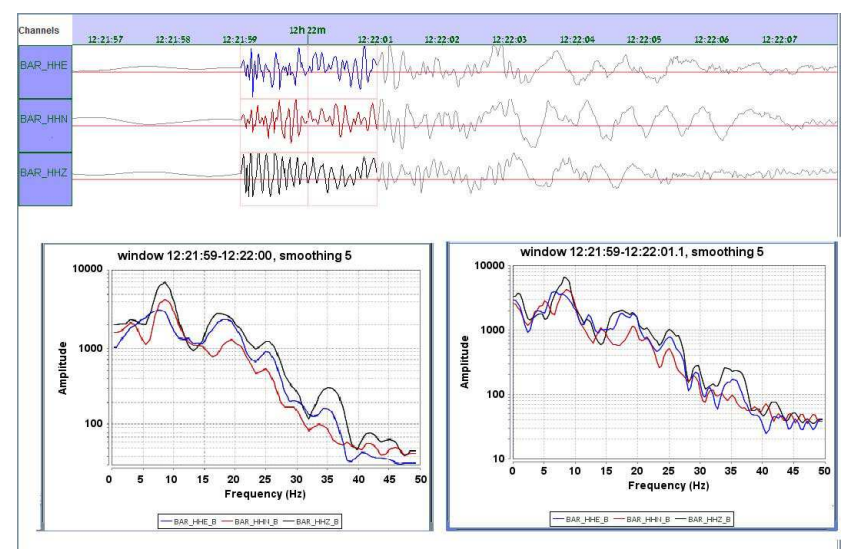

Figure 4. P-wave spectra for $1 \mathrm{~s}$ time window (left) and P-wave spectra for $2.1 \mathrm{~s}$ time window (right). The bubble pulse $(1.01 \mathrm{~Hz})$ is not observed in the short time window but is observed in the long time window because the bubble pulse arrives 0.990 seconds later after the P-wave arrival.

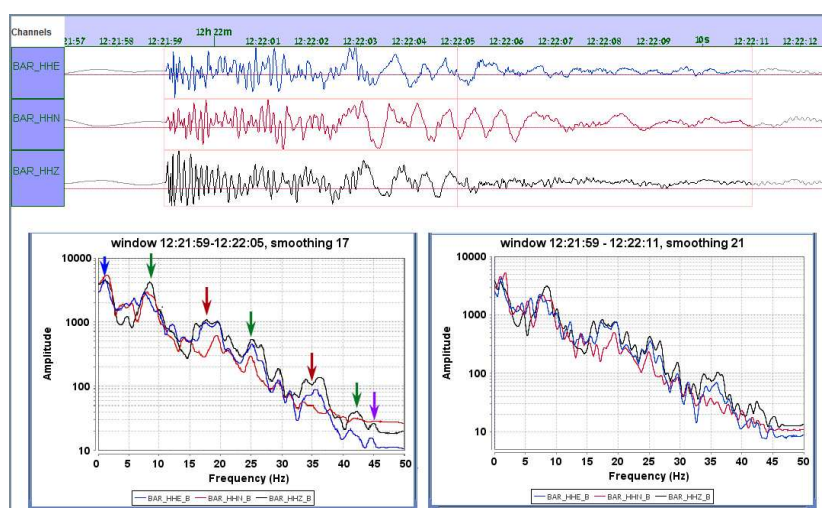

Figure 5. Spectra of the summation of $P$ and surface waves for a short time window (6 s) and a long time window (12 s). Blue, green, red, and purple arrows indicate bubble pulse, cutoff frequency from bottom, nonlinear shock waves, and cutoff frequency from the surface, respectively.

The bubble pulse $(1.01 \mathrm{~Hz})$, bottom reflection cutoff frequencies $(8.5 \mathrm{~Hz}, 25 \mathrm{~Hz}$, and $43 \mathrm{~Hz}$ ), and the free surface reflection cutoff frequency $(45 \mathrm{~Hz})$ are clearly observed. The broad spectral peaks on the radial components (UD and EW) at around $17.5 \mathrm{~Hz}$ and $35 \mathrm{~Hz}$ may be related to nonlinear shock waves. Ocean depth $(\mathrm{H})$, detonation depth (d), and net explosive charge weight (W) $-\mathrm{H} \approx 44 \mathrm{~m}[\mathrm{H}=(1500 \mathrm{~m} / \mathrm{s}) / 4 \mathrm{x} 8.5 \mathrm{~Hz}], \mathrm{d} \approx 8 \mathrm{~m}[\mathrm{~d}=$ $(\approx 1500 \mathrm{~m} / \mathrm{s}) / 4 \times 45 \mathrm{~Hz}]$, and $\mathrm{W} \approx 136 \mathrm{~kg}$ TNT $\left[\mathrm{T}=2.1 \mathrm{~W}^{1 / 3} /(10.1+\mathrm{d})\right]$ where $\mathrm{T}=$ bubble pulse period 0.990 $\mathrm{s}$ - were estimated from the cutoff frequencies of the first harmonic mode from both the bottom and surface reflections as well as the bubble pulse period from previous study [1-2] neglecting free surface effect due to the UWE off beneath the hull of the ship . Provided the detonation depth via the cutoff frequency and the bubble pulse period are determined from spectral analysis, it is possible directly to estimate the amount of the NEW without testing the detonation depth piecemeal for each different case which was shown in Kim and Gitterman [1].

\section{Conclusion}

Cutoff frequencies of the reflections off the ocean bottom and the surface as well as the bubble pulse were analyzed for this shallow underwater explosion via spectral analysis based on normal modes and ray-tracing method. The cutoff frequency of $45 \mathrm{~Hz}$ on the surface reflection indicates a NEW of approximately $136 \mathrm{~kg}$ TNT at a detonation depth of $8 \mathrm{~m}$ vis-à-vis the ROKS Cheonan and those findings are also espoused by the ray-trace modeling as well as the previous studies [1-2] that the pressure impulse on the hull of the ship during jet impact and the vortex of the toroidal bubble indicate that the high-speed liquid jet has a significant potential for causing severe damage to a ship.

\section{References}

[1] S. G. Kim, and Y. Gitterman, "Underwater explosion (UWE) analysis of the ROKS Cheonan Incident," Pure and Applied Geophysics, vol. 170, pp. 547-560, 2013. DOI:10.1007/ s00024-012-0554-9.

[2] S. G. Kim, "Forensic seismology and boundary element method application vis-à-vis the ROKS Cheonan underwater explosion," Journal of Marine Science and Application, vol. 12, pp. 422-433, 2013. DOI: 10.1007/ s11804-013-1213-y.

[3] B. Nicolas, J. Mars, and J. Lacome, "Geoacoustical parameters estimation with impulsive and boat noise sources," IREE J. of Oceanic Engineering, vol. 28 (3), pp. 494-503, 2003.

[4] R. J. Urick, Principles of Underwater Sound. $3^{\text {rd }}$ edn, McGraw-Hill Book Company, New York, pp. 172-201, 1983.

[5] X. Lurton, An Introduction to Underwater Acoustics: Principles and Applications. Praxis Publishing, Chichester, UK. pp. 13-58, 2002.

[6] O. C. Rodriguez, J. Collis, J. Simpson, E. Ey, J. Scheiderwind, and P. Felissberto, "Seismo- acoustic ray model benchmarking against experimental tank data," J. of Acoust. Soc. Am. vol. 132 (2), pp. 709-717, 2012.

[7] M. B. Porter and H. P. Bucker, "Gaussian beam tracing for computing ocean acoustic Fields," J. of Acoust. Soc. Am. vol. 82 (4), pp. 1349-1359, 1987.

[8] A. Shapira, "T phases from underwater explosions off the coast of Israel," Bull. Seism. Soc. Am. vol. 71 (4), pp. 1049$1059,1981$.

[9] D.E. Weston, "Wave shifts, beam shifts, and their role in modal and adiabatic propagation," J. of Acoust. Soc. Am. vol. 96 (1), pp. 406-417, 1994.

[10] C. T. Tindle, D. E. Weston, and S. G. Payne, "Cycle distances and attenuation in shallow water," J. of Acoust. Soc. Am. vol. 68 (5), pp. 1489-1492, 1980. 